\title{
СКРЫТОЕ РАЗНООБРАЗИЕ ГРИБОВ И ГРИБООБРАЗНЫХ ПРОТИСТОВ В ПРИРОДНЫХ ЭКОСИСТЕМАХ: ПРОБЛЕМЫ И ПЕРСПЕКТИВЫ Ю.К. Новожилов ${ }^{* 1}$, В.Ф. Малышева ${ }^{1}$, Е.Ф. Малышева ${ }^{1}$, О.Н. Щепин ${ }^{1}$, Д.В. Азаров ${ }^{2}$, И.В. Змитрович ${ }^{1}$, С.В. Волобуев ${ }^{1}$, А.Е. Коваленко ${ }^{1}$ \\ ${ }^{1}$ Ботанический институт им. В.Л. Комарова Российской академии наук и \\ ${ }^{2}$ Северо-Западный государственный медицинский университет им. И.И. Мечникова, Санкт-Петербург, Россия \\ * Эл.noчma: yurinovozhilov@gmail.com \\ Статья поступила в редакиию 16.05.2016; принята к печати 06.06.2016
}

За последние годы достигнут значительный прогресс в изучении скрытого разнообразия грибов и грибообразных протистов (Myхотусеtes = Mycetozoa) в связи с ростом использования методов секвенирования следующего поколения (NGS). В этом обзоре мы подвели итоги исследований почвенных грибов, включая эктомикоризные грибы, сапротрофные аскомицеты, базидиомицеты и миксомицеты, а также дереворазрушающих грибов, с акцентом на последствия пожаров для этих организмов. Также обсуждены несколько направлений в этих исследованиях, включая методы и подходы.

Ключевые слова: биоразнообразие, молекулярная экология, грибы, протисты, пожары.

\section{HIDDEN DIVERSITY OF FUNGI AND FUNGUS-LIKE PROTISTS IN NATURAL} ECOSYSTEMS: PROBLEMS AND PROSPECTS

Yu.K. Novozhilov ${ }^{1 *}$, V.F. Malysheva ${ }^{1}$, Ye.F. Malysheva1, O.N. Schepin', D.V. Azarov ${ }^{2}$, I.V. Zmitrovich ${ }^{1}$, S.V. Volobuev ${ }^{1}$, A.Ye. Kovalenko ${ }^{1}$

${ }^{1}$ V.L. Komarov Boranical Institurte of the Russian Academy of Sciences and ${ }^{2}$ I.I. Mechnikov Northwest State Medical Institute of Saint Petersburg, Saint Petersburg, Russia

*E-mail:yurinovozhilov@gmail.com

Significant progress has been made in recent years in our understanding of the hidden diversity of fungi and fungus-like protists (Myxomycetes = Mусеtozoa) due to the increasing application of the next-generation sequencing technologies (NGS). In this review, we summarize advances in hidden diversity research of soil fungi, including ectomycorrhizal fungi, saprotrophic ascomycetes, basidiomycetes, and myxomycetes, as well as xylophilic fungi, with emphasis on the effects of fire on these organisms. We also discuss several directions of future research in this field, including methods and approaches.

Keywords: biodiversity, molecular ecology, fungi, protists, fires.

\section{Введение}

Грибы (Fungi) и грибообразные протисты (Myхоmycetes $=$ Eumycetozoa $)$ представляют собой один из наименее исследованных компонентов разнообразия эукариот в экосистемах Земли. Между тем, эти организмы являются важнейшим компонентом наземных экосистем планеты как по биомассе, так и по функциональной роли, которую они играют в качестве деструкторов, патогенов и регуляторов численности популяций других микроорганизмов. Формируя микоризу, грибы способны влиять на паттерны и направления растительных сукцессий, а также опосредованно на формирование и развитие растительных сообществ в целом [102].

Трансформация экосистем под воздействием антропогенных и природных факторов драматически сказывается на структуре и составе грибных сообществ, однако природа и основные тренды этих изменений остаются все еще малоизученными, что свя- зано со значительными пробелами в знании об их видовом и экологическом разнообразии, а также географическом распространении.

Очевидно, что информация о видовом составе, характере взаимодействий грибов и грибообразных протистов в почве имеет решающее значение для понимания механизмов формирования стабильных, сбалансированных отношений не только в сложных микробных ассоциациях, но и в фитоценозах в целом. Эти данные крайне важны не только для микологии, микробиологии и протистологии, но также для междисциплинарных отраслей знаний, таких как экология, фитоценология, лесное и сельское хозяйство.

\section{Концепции и методы}

Оценка реального количества видов грибов и протистов в природе всегда была существенной проблемой, прежде всего из-за особенностей их жизненного цикла. Вегетативные или трофические стадии (мице- 
лий грибов, плазмодии и амебы миксомицетов) скрыты от глаз исследователя. К тому же подавляющее большинство таксонов описано на основании морфологических признаков плодовых тел, что ведет к сильному занижению таксономического разнообразия из-за высокой распространенности «видов-двойников» [34, 113, 114, 133].

Следует подчеркнуть, что в классических исследованиях состав грибных сообществ почвы и непосредственно ризосферы оценивался преимущественно путем выращивания изъятых из среды грибных пропагул на подходящих питательных средах в чистой культуре. Что касается микоризообразователей, то их выявление сводилось к идентификации видимых надземных плодовых тел по традиционно используемым для этого морфологическим признакам. Благодаря исследованиям ex situ был выявлен довольно впечатляющий объем новых видов [38]. Тем не менее, многочисленные примеры подобных работ на бактериальных объектах показали, что методы культивирования неточны, поскольку до 90\% микробного разнообразия не поддается выявлению в подобных исследованиях [154]. Таким образом, важная проблема, не решаемая с применением классической таксономии и техники чистых культур, - это существование криптических видов, которые могут доминировать в образце субстрата $[75,125,137]$, но не растут на искусственных средах. Уровень видового разнообразия таких групп довольно высок и не выявляется без применения молекулярных методов, а генетическое расстояние между выявляемыми последовательностями так называемых операционных таксономических единиц (см. ниже), относящимися к неизвестным группам грибов, часто примерно соответствует уровню межвидовых отличий многих эукариот или даже более высоким таксономическим уровням [13].

Начиная с последней декады прошлого века использование молекулярных методов анализа ДНК, выделенной из субстратов, стало применяться все чаще и дало новый импульс к изучению скрытого видового разнообразия грибов и миксомицетов, а также их функциональных характеристик в сообществах $[10,11,18,30,37,54,78,81,92,93,96,114,116$, $118,124,145,158]$.

В настоящее время наиболее успешными методами выявления скрытого разнообразия организмов в среде обитания (hidden diversity) является группа молекулярно-генетических методов, включающая технологию секвенирования по Сэнгеру, оценку рестрикционных профилей $(R F L P)$ и следующее поколение технологий секвенирования (NGS, next generation sequencing).

Последним методам посвящен специальный выпуск журнала Molecular Ecology [142]. Методы NGS применяются в метагеномных исследованиях, которые обычно состоят из нескольких этапов: выделение ДНК из природных субстратов, фрагментация ДНК на отрезки определенной длины (или амплификации маркерных последовательностей) и секвенирование полученных ДНК-библиотек на одной из NGS-платформ (Illumina, 454, Ion Torrent и т. д.) с дальнейшей биоинформатической обработкой. Хотя все они не лишены некоторых ограничений и не свободны от определенной доли предвзятости в интерпретации результатов, они позволяют исследовать разнообразие прокариот, грибов и протистов на небывалой ранее высоте таксономического разрешения $[20,114]$.

Это оказывает решающее влияние на интерпретацию как разнообразия, так и биогеографических моделей и процессов, определяющих закономерности видообразования и распространения микроорганизмов, включая как прокариот, так и эукариот. Использование этих подходов для изучения грибного разнообразия без выделения грибов из окружающей среды в чистые культуры было начато в первые годы нового тысячелетия, однако стало набирать популярность лишь в последние пять лет в связи с увеличением доступности методов NGS. Современное состояние развития этой молодой науки (метагеномики) характеризуется активным накоплением первичных данных и созданием международных баз данных [13, 27, 84, 85 , $93,158]$. В частности, эти исследования указывают на существование большого числа почвенных видов грибов, остающихся за полем зрения при использовании иных методов их выявления [90, 92, 113].

Наблюдаемое увеличение массива таксономической информации в большой степени связано с применением молекулярных технологий как дополнительного метода исследования в традиционной «морфологической» систематике, а также с интенсификацией экологических работ, связанных с молекулярным изучением грибов непосредственно в среде обитания (в так называемых environmental samples - почве, корнях, подстилке, древесине и других субстратах). Использование ДНК для видовой идентификации грибов в микоценозах или микробных консорциумах приводит к новому пониманию разнообразия этих сообществ $[75,127]$. В данном случае, при отсутствии макро- и микроскопических структур, доступных для изучения, критерием разграничения таксонов является алгоритм кластеризации полученных нуклеотидных последовательностей, основанный на их сравнении с эталонными последовательностями при определенном пороговом значении, выбор которого варьирует в разных исследованиях, но обычно составляет 97\% сходства (дивергенция 0,03). Для присвоения таксономических имен используются справочные доступные базы данных - GenBank и UNITE $[6,17,85]$. Такие кластеры нуклеотидных последовательностей, объединенные сходством и разграниченные генетической дистанцией, не соответствуют ни одному принятому критерию вида, поэтому их часто называют операционными таксономическими единииами (в иностранной литературе это operational taxonomic units (OTU) или molecular operational taxonomic units (MOTU). При этом они могут соответствовать любому уровню таксономической иерархии и организации живого - от единичного организма (или одиночной нуклеотидной последовательности) и отдельных популяций до рода, семейства и выше. Тем не менее, в практике экологических исследований они рассматриваются в основном как отдельные виды в случае оценки видового разнообразия [119]. Целесообразность представления видового разнообразия сообществ в виде OTU зависит от многих причин, в том числе от того, насколько верно использован порог кластеризации и насколько изменчив генетический маркер, чтобы избежать ошибок в разграничении таксонов на уровне вида. Кроме того, трудностям в определении так- 
сономической принадлежности OTU способствует неполнота существующих баз данных референсных маркерных последовательностей, поскольку далеко не для всех описанных на данный момент видов грибов и грибообразных протистов имеются последовательности хотя бы одного маркерного гена.

По оценке одного из известных микологов Дэвида Хиббетта [70], огромное число OTU в образцах субстрата из окружающей среды, выявляемое NGSтехнологиями, может представлять собой скрытое разнообразие видов - как уже описанных с помощью стандартных морфологических и культуральных методов, так и не известных науке $[20,36,40,103,112$, $114,151]$

Ежегодный прогресс в описании новых таксонов грибов и протистов впечатляет. По данным обобщенных исследований, в период с 1999 по 2009 г. в среднем описывалось по 1196 видов грибов ежегодно [71]. В настоящее время тенденция сохраняется, и это позволяет смело оценивать общее разнообразие грибов в 1,5 миллиона $[21,67]$ или даже в $3,5-5,0$ миллионов видов [109], а разнообразие протистов - примерно в 1 миллион [118]. Исходя из этих оценок видно, что к настоящему времени выявлено не более 7\% видов грибов и $0,5 \%$ протистов среди существующих на земле. Впрочем, последние данные метагеномного анализа почвенных микромицетов указывают на то, что эти цифры могут быть завышены в 1,5-2,5 раза [148].

Почва представляет собой гигантский резервуар скрытого разнообразия грибов и протистов. Например, было показано, что последовательности, относящиеся к грибам, были наиболее многочисленными из всех представителей Opisthokonta и составляли до $60 \%$ последовательностей матричной РНК, выделенной из почв буковых и еловых лесов Европы [33]. Почвенная среда включает в себя разнообразные грибные сообщества, которые могут получать энергию как от мутуалистических или паразитических взаимодействий с высшими растениями, так и из разнообразных органических субстратов почвенного матрикса. Несмотря на его очевидную важность в функционировании экосистем, грибное видовое богатство еще мало изучено. Первоначальные исследования почвенной биоты сводились к биогеографии и экологии исключительно микробного компонента или к сравнению между почвообитающими макро- и микроорганизмами.

Исследования разнообразия почвенных грибных сообществ, проводимые с помощью NGS, были или сосредоточены на филогенетически ограниченном наборе таксонов, например, эндомикоризных грибах [40], или выполнены на ограниченном (локальном или региональном) пространственном масштабе $[90,132,147]$.

Центр внимания в настоящее время смещается к выявлению не только и не столько качественной структуры биоты, сколько, прежде всего, механизмов, определяющих наблюдаемые биогеографические модели их распространения [57, 58, 64, 98]. Показано, что взаимоотношения внутри субстратных группировок грибов и грибообразных организмов могут существенно отличаться от таковых у бактериального компонента почв [122]. Однако очень незначительная доля проводимых в настоящее время исследований пространственных группировок грибов и разнообразия их в почвах использует моле- кулярные технологии секвенирования (в том числе NGS-технологии), которые могут дать существенные преимущества в оценке скрытого разнообразия и являются на сегодня пока единственным адекватным механизмом его выявления [27, 92, 100, 114, 118].

В данном обзоре мы постараемся охарактеризовать первые результаты метагеномных исследований в изучении скрытого разнообразия грибов и грибообразных протистов почв, а также влияния на них лесных пожаров как одного из наиболее мощных и очевидных факторов, способных влиять на сообщества грибов и протистов в верхнем горизонте почв.

\section{Скрытое разнообразие эктомикоризообразователей}

Все более очевидно, что симбиозы на уровне сложных организмов являются скорее правилом, чем исключением. Накопленные данные свидетельствуют о том, что более $85 \%$ всех наземных растений получают минеральное питание через облигатные микоризные ассоциации с грибами [25]. Среди различных видов взаимоотношений между растениями и грибами эктомикоризный (ЭМ) симбиоз - один из широко распространенных типов симбиоза в природе. В сравнении с эндомикоризным симбиозом (арбускулярной микоризой), который образуют $80 \%$ всех растений, в эктомикоризные ассоциации вовлечено только $2 \%$ из них. Несмотря на это, крупнейшие биомы на планете находятся в прямой зависимости именно от ЭМ-грибов. К экологически и экономически значимым древесным растениям, формирующим ЭМ, относятся представители таких семейств, как Pinaceae, Fagaceae, Nothofagaceae, Betulaceae, Myrtaceae, Dipterocarрасеае - основа хвойных и широколиственных лесов умеренного пояса, лесов средиземноморского типа, а также саванн, тропических и субтропических лесов Южной Америки, Африки, Юго-Восточной Азии, Индии и Австралии $[9,126,146]$. Нормальный рост отдельных деревьев и сеянцев, а также сохранение целых экосистем напрямую зависят от колонизации растений микоризными грибами.

Согласно основной концепции, эктомикориза рассматривается как проявление сбалансированного реципрокного паразитизма между растениями и грибами, в природных условиях реализованного как мутуалистический симбиоз [41]. Однако в антропогенных условиях или под влиянием каких-либо неблагоприятных факторов среды может происходить сдвиг данного баланса, позволяющий одному из партнеров получить явное доминирование. В этом способе совместного существования растения обеспечивают грибного партнера продуктами фотосинтеза, тогда как микобионт поставляет хозяину воду, растворенные и органически связанные питательные вещества, особенно азот и фосфор. Грибы могут также выполнять другие положительные функции, такие как защиту растения от неблагоприятных факторов окружающей среды и стресса, вызванных химическими веществами, патогенами или засухой [136].

В отличие от грибов, участвующих в образовании арбускулярной и эрикоидной микориз, большинство эктомикоризных грибов (ЭМГ) имеют половую стадию в своем развитии, то есть продуцируют, как правило, макроскопические плодовые тела - надземные или подземные. Среди них большинство известных грибов с шляпочными и распростертыми по суб- 
страту (древесине, подстилке) плодовыми телами, а также гипогейные представители (например, трюфели). Однако это простое определение не соответствует реальному многообразию и сложности ЭМГ как единой экологической группы. Таксономические и молекулярные исследования последних лет показали, что эктомикоризный способ питания возникал многократно в результате конвергентной эволюции в разных группах грибов $[26,68,69,146]$. Сейчас известно около 10000 ЭМГ из трех крупных таксономических групп: Zygomycota, Ascomycota и Basidiomycota, с доминированием последней в их общем разнообразии [144].

Проблема изучения сообществ ЭМГ крайне актуальна. Их разнообразие очень высоко, и, как показано выше, они играют важную роль в функционировании отдельных фитоценозов и целых экосистем. Однако, несмотря на довольно большое число публикаций и возрастание числа исследований во всем мире по данной тематике за последние несколько десятков лет, исследователи все еще далеки от ответа на многие вопросы, касающиеся эктомикоризы как природного феномена. Какое реальное соотношение числа и обилия видов в структуре сообществ ЭМГ? Как меняются эти сообщества в зависимости от состава фитоценоза, почв и других условий среды? Как реагируют группировки ЭМГ на смену растительных сообществ, и могут ли, наоборот, изменения микоценоза повлиять на ход сукцессии фитоценоза? Ответы на эти вопросы требуют решения ряда проблем, связанных как с самими ЭМГ, так и методами их изучения.

Традиционные методы идентификации грибов на основе сбора и характеристики плодовых тел не позволяют выявить адекватно весь набор микоризообразователей на той или иной территории. Это часто связано с явлением спорадического плодоношения у многих видов ЭМГ, а также со сложностями в определении таксонов ввиду частого отсутствия четких морфологических критериев для разграничения близкородственных видов $[74,75,135,136]$. Вегетативные структуры ЭМГ (мицелий и микоризные окончания) скрыты от непосредственного наблюдения, а также труднодоступны для отбора в природе, так как полностью располагаются в субстрате, иногда на довольно большой глубине. Но даже если удастся осуществить в природе трудоемкий сбор микоризных окончаний, то таксономическое определение грибного компонента микориз по морфологии и анатомии эктомикоризного корневого чехла [8] все равно не может обеспечить идентификацию видов с высокой точностью и разграничить близкородственные таксоны, поскольку вся систематика грибов до сих пор была основана на признаках плодовых тел (то есть половой стадии) [74, 157]. По этой причине в большинстве ранних публикаций, имеющих дело с данными способами идентификации ЭМГ, очень много таксонов оставалось не идентифицированными даже до рода. Часто авторы имели дело с так называемыми «туманными» или «неясными» видами, лишь приблизительно отражающими реальное разнообразие изучаемой группы [75]. Другой известной проблемой изучения ЭМГ является сложность использования методов стерильного культивирования и микрокосма (нестерильное культивирование) для проведения исследований в лабораторных условиях и дальнейшей экстраполяции результатов на природные сообщества. Несмотря на то что некоторые позитивные результаты все же получены в отношении изучения экологии и физиологии отдельных видов ЭМГ в лаборатории (таких, например, как Suillus, Rhizopogon, Paxillus, Laccaria, Pisolithus и Cenococcum), подавляющее большинство грибов не поддаются изучению данными методами $[22,35,131]$.

Молекулярные методы идентификации ЭМГ, основанные на выделении ДНК непосредственно из материала микоризных окончаний (root tips) или мицелия в почве и секвенировании отдельных участков генома, становятся сейчас одним из наиболее эффективных подходов в изучении грибных сообществ. Эти методы дают возможность наиболее достоверного определения таксонов на родовом и видовом уровнях $[74,89]$. В настоящее время для проведения перспективных молекулярных исследований «стандартным набором» молекулярных маркеров выступает внутренний траскрибируемый спейсерный участок рибосомальной ДНК (internal transcribed spacer ITS), гены фактора-1 трансляционной элонгации (translation elongation factor 1 TEF1), гены субъединиц РНКполимеразы II (rpb1 и rpb2) и ген малой субъединицы митохондриальных рибосом (mitochondrial small subunit rDNA, SSU).

Однако довольно примечательным результатом использования молекулярного подхода при изучении микориз является обнаружение явного несоответствия между разнообразием сообществ ЭМГ, которое оценивается классическими методами по плодовым телам (above-ground diversity), с тем разнообразием, которое выявляется при анализе ДНК из микоризных окончаний (below-ground diversity) [32, 60, 61, 78, 99, 153].

Лишь единичные виды ЭМГ демонстрируют довольно постоянное соответствие между обилием плодовых тел и частотой встречаемости в микоризных окончаниях. К таким видам относятся, например, Suillus pungens и Amanita francheti [60], некоторые виды гипогейных грибов и некоторые представители рода Lactarius [95]. Однако, как правило, подавляющее большинство видов грибов, обильно плодоносящих в сообществе, редко проявляют такое же обилие в формировании микоризных чехлов, и, наоборот, у большинства видов, выявляемых из микоризных окончаний (от 70 до $80 \%$ общего разнообразия), не отмечается наличие спорокарпов [32].

Все микоризные грибы проходят в своем развитии «внекорневую фазу», причем в отношении специализированных групп микоризообразователей предполагается, что «поисковый рост» лимитирован энергетическим и пластическим резервом соответствующих пропагул [23], в то время как для ряда эктомикоризообразователей фиксируется выраженная сапротрофная активность [43]. Успешная колонизация новых корневых окончаний поисковым мицелием, развивающимся в почве, на молекулярном уровне регулируется процессами «узнавания» и возможна далеко не для всех прорастающих пропагул [135]. Это может быть причиной переоценки реального разнообразия эктомикоризообразователей, выявляемых в рассматриваемом сообществе молекулярными методами.

Следует подчеркнуть, несмотря на то, что интерес к проблеме микоризного симбиоза растет во всем 
мире, большинство работ в настоящее время принадлежит зарубежным авторам, и лишь малая часть публикаций - российским ученым $(1,4-6,65,105,117$, 123). Исследования по данной тематике, основанные на методах NGS, в России до настоящего момента не проводились. В мире в настоящее время действует несколько крупных проектов с использованием метагеномного анализа и NGS. Например, это международный проект исследования эктомикоризных ассоциаций на основе изучения грибного симбионта непосредственно в корневых окончаниях и субстрате молекулярными методами (Ectomycorrhizal fungal diversity of the central Guiana Shield), реализуемый лабораторией отделения биологии университета Дьюка (Дурхэм, США) $)^{1}$, и недавно стартовавший крупный американский проект Dimensions of Ectomycorrhizal Diversity (DoED) по изучению эктомикориз с применением новых молекулярных методов (в том числе NGS-технологий), реализуемый группой лабораторий Peay Lab (Stanford University), Bruns Lab и Taylor Lab (UC Berkeley) и Vilgalys Lab (Duke University) ${ }^{2}$.

\section{Скрытое разнообразие сапротрофных аско- и базидиомицетов}

Сапротрофные высшие грибы играют важнейшую роль в экосистемах как разрушители органики растительного происхождения. В таежных лесах очагами их разнообразия являются ветровально-почвенные комплексы, где параллельно происходят процессы гумификации древесины и возобновления древесной растительности $[1,4,14,77,86,106,115]$. Сапротрофные грибы регулируют ключевое звено воспроизводства таежных экосистем - преобразование древесного детрита в подстилку и гуматно-фульватный пул в условиях избыточного увлажнения. К последней стадии гумификации крупномерных хвойных и лиственных пород приурочен практически один и тот же набор видов грибов - подстилочных и гумусовых лигнотрофов $[4,14,77]$.

Исследование грибов в листовой подстилке молекулярными методами, включая методы NGS и технологию GeoChip, проводилось в контексте изучения их способности разрушать различные органические компоненты опада на временном градиенте, а также в различных горизонтах опада и почвы. В частности, было показано, что биомасса грибов больше в слое опада ели по сравнению с бактериями, тогда как в органическом горизонте почвы их биомассы сопоставимы. Кроме того, разнообразие грибов в органическом горизонте почвы значительно ниже, чем в опаде [16, 152].

Высшие грибы участвуют в замыкании цикла биогенных элементов, контролируя ключевые точки воспроизводства таежных экосистем. Сапротрофы часто доминируют в почвенных микобиомах и могут играть роль эдификаторов в отношении сообществ микромицетов. В то же время эти грибы - наименее изученная с применением NGS-технологий экологическая группа. Отдельные исследования, которые все же проводились в этом направлении, показывают их высокое разнообразие в почвенных пробах [27, 132, 148]. Метагеномный анализ позволил выявить ряд трендов в изменении видового состава почвенных аскомицетов в тундрах Аляски в ответ на изменение

${ }^{1} \mathrm{http}: / /$ tropicalfungi.org/project-summary/

${ }^{2} \mathrm{http}: / /$ www.stanford.edu/ kpeay/DOB_Home.html климата. Например, изменение скрытого разнообразия аскомицетов почв коррелировало с уменьшением численности мхов и лишайников и увеличением площади покрытия кустарников в ответ на потепление климата в арктических растительных сообществах. Причем характер этих изменений отличался в сухих и влажных тундрах [132].

\section{Скрытое разнообразие миксомицетов}

Амебоидные простейшие Amoebozoa - одна из наиболее многочисленных и важных частей биоты почвенных эукариот. Последние исследования, проводимые с помощью метагеномного анализа, выявили огромное число неизвестных таксонов протистов (OTU), которые пока с трудом поддаются традиционной таксономической интерпретации [20].

Миксомицеты (Myxomycetes = Myxogastria), или грибообразные протисты, относятся к филогенической линии Amoebozoa [7], объединены в пять порядков и насчитывают около 900 морфовидов [130]. Они являются традиционным объектом исследований микологов, поскольку формируют спорокарпы, которые напоминают плодовые тела некоторых грибов и легко сохраняются в микологических гербариях. Это одна из наиболее древних групп амебоидных организмов, возникшая, видимо, до появления наземных растений [56]. Их роль в почвенных экосистемах отличается от роли грибов. Они влияют на численность других микроорганизмов [138-140], поскольку псевдоподии амеб миксомицетов могут проникать через поры частиц почвы, не превышающие 6 мкм в диаметре, и поедать там бактерии, дрожжи и микроводоросли, которые практически недоступны для других простейших [42].

В ранних работах, основанных на подсчете амеб и плазмодиев в культурах, была отмечена их исключительно высокая плотность в верхних горизонтах некоторых типов почв в умеренном климате [44-48]. Было показано, что миксомицеты значительно чаще встречаются в почвах травянистых растительных сообществ, чем в лесных почвах. Однако метод изоляции миксомицетов на агаровых средах в культурах давал явно завышенные результаты в отношении видов порядка Physarales, которые наиболее легко культивируются в лаборатории. Кроме того, значительная часть изолятов плазмодиев и амеб не образовывала плодовых тел, что делало невозможным их определение до вида традиционными морфологическими методами.

На основании результатов оценки слияния плазмодиев из разных изолятов в условиях культуры было показано, что один генетический штамм одного вида может занимать площадь до 1,3 км² [139]. Интересно, что подобная закономерность захвата большой территории одним бесполым клоном была также выявлена среди диктиостелиевых миксомицетов [62]. Однако, как подчеркивают сами авторы, эти результаты могут быть связаны с повышенной способностью данных клонов к культивированию на искусственных средах.

Новая эра в исследованиях скрытого разнообразия миксомицетов в различных экосистемах началась в новом тысячелетии $[15,33,101]$. Анализ биоты почв, проведенный на очень большом сравнительном материале методами метатранскриптомики (анализ РНК в образце на основе комплементарной ДНК, получа- 
емой при помощи обратной транскрипции), показал, что миксомицеты представляют около $25 \%$ общего разнообразия протистов в одном образце почвы $[15$, 151]. Напротив, при использовании методов метагеномики миксомицеты практически не выявлялись в образцах почвы [91]. Это противоречие недавно нашло свое объяснение $[80,140]$ и разрешение. Авторы считают, что первые неудачные попытки выявления миксомицетов в образцах почв методами метагеномики связаны в значительном различии последовательностей гена малой рибосомной субъединицы (SSU) у разных видов, в том числе по длине $[52,55]$.

Соответственно, универсальные для других Amoеbozoa праймеры не подходят для миксомицетов даже для консервативных участков гена SSU. Кроме того, ген SSU содержит большое число интронов различной длины, которые могут занимать до 70\% всей последовательности [49, 50, 155, 156].

В связи с этим значительные усилия были потрачены в последнее время на дизайн соответствующих праймеров, в частности, для ДНК-штрихкодирования (баркодинга) миксомицетов [51, 97]. В результате была показана перспективность использования для этих целей маркерной последовательности первой части гена SSU (около 600 пн), свободной от интронов, а также гена tef1- $\alpha$ [51-53, 107, 108]. Для темноспоровых миксомицетов данный ген относительно легко идентифицируется по уникальной подписи в его начале ТСТСТСТ $[80,118]$.

Недавно проведенное нами исследование, главным образом темно-споровых нивальных миксомицетов [107], показало, что данный маркер хорошо выявляет почти все изученные морфовиды, однако многие из них включают по несколько генотипов («риботипов»). Так же как у других групп протистов, среди миксомицетов можно ожидать выявление большого числа криптических видов. Практически для всех миксомицетов, изученных с использованием данного маркера, отношение генотипов к морфовидам варьировало между $1: 5$ и $1: 25$.

Ген tef1- $\alpha$ также достаточно вариабелен и пригоден для выявления морфовидов [110]. К настоящему времени для примерно 50 морфовидов известны его последовательности. Ген субъединицы 1 митохондриальной цитохромоксидазы (COI) относится к менее вариабильным, однако широко используется в филогении протистов. Крайне необходимы дальнейшие исследования по проверке этого маркера в отношении разных групп миксомицетов [94]. Кроме перечисленных маркерных генов при изучении видов рода Fuligo были использованы внутренний транскрибируемый спейсер (ITS) гена рибосомной РНК и короткий участок (около 250 пн) митохондриального гена $16 \mathrm{~S}$ рРНК [73]. Однако в отношении этих двух маркеров данных еще недостаточно, чтобы судить о возможностях их использования для баркодинга миксомицетов.

\section{Скрытое разнообразие микобиоты на различных стадиях восстановления после лесных пожаров}

Особый интерес представляет изучение изменения скрытого разнообразия в уязвимых лесных экосистемах на различных стадиях восстановления после природных катастроф, которое не выявляется стандартными морфолого-таксономическими и культуральными методами. Актуальность таких исследований связана с нарастающей антропогенной трансформацией природной среды и вытекающей из этого необходимостью поиска надежных методов оценки состояния экосистем и прогнозирования их возможных изменений. Изучение сукцессий микроорганизмов после пожара дает богатый материал по изучению межвидовых взаимодействий и анализа ниш видов в составе пионерных сообществ.

Естественные пожары, так же как и организованные специально человеком палы, являются одним из самых мощных факторов, влияющих на экосистемы $[2,3,5,104,105]$.

Эффекты, связанные с влиянием пожаров, достаточно хорошо установлены. Известно, что пожары могут оказывать как прямое, так и опосредованное влияние на почвенные экосистемы $[65,66,129,150]$. Сила и характер их воздействия зависят от многих факторов, таких как частота возникновения, интенсивность пожара, сезонность, влажность почвы и др. [96].

В результате прямого воздействия пожаров происходит уничтожение растительности, выгорание органического горизонта и перегрев почвы, выброс азота и углерода в атмосферу, отложение и выпадение угля и пепла [28] и др. Опосредованными (непрямыми) следствиями пожаров является изменение влажности и $\mathrm{pH}$ почвы по мере усиления ее эрозии, а также физического и химического воздействия угля на окружающую среду $[28,66]$.

Изменения геохимических процессов, например, ослабление минерализации азота, также связаны с последствиями пожара [63]. После пожара происходят изменения в количестве и качестве растительного опада, а также во взаимоотношениях между растениями, микроорганизмами и грибами [31]. Поскольку эффект нагревания от пожара наиболее сильный в органическом горизонте почвы и в нескольких сантиметрах верхнего минерального горизонта, его воздействие на почвенные микроорганизмы (особенно вблизи поверхности почвы) может быть очень значительным [104, 105].

Известно, что эктомикоризные (ЭМ) грибы наиболее чувствительны к пожарам [72]. Однако имеются виды, устойчивые к воздействию пожара, например, виды рода Wilcoxina [82], Russula, Suillus [76] и Rhizopogon [82]. Более того, несмотря на эффект снижения грибной биомассы после пожара, некоторые грибы положительно реагируют на его воздействие $[12,82]$.

В ряде работ показано, что пожары влияют на структуру грибных сообществ наряду с увеличением или наоборот уменьшением способности микоризы колонизировать корни растений [18, 28, 31, 149]. В районах, где пожары происходят регулярно, эффект воздействия прямо зависит от частоты пожаров. Однако, несмотря на то что пожары могут приводить к структурным изменениям в почвенных грибных сообществах, функциональное значение подобных изменений на уровне всей экосистемы пока трудно проанализировать. Это во многом связано с методическими проблемами оценки встречаемости отдельных компонентов микобиоты и силы влияния пожара на грибные сообщества в целом. Делаются только первые попытки связать конкретные группы и таксоны грибов с физическими и геохимическими процессами, происходящими в экосистемах после пожара 
[141]. В частности, результаты исследований, проведенных на Аляске с помощью анализа кислых фосфолипидов, количественного анализа эргостеролов, оценки длины гиф и культуральных методов, показали, что пожар не оказывал существенного влияния на общую биомассу грибов или концентрацию пропагул [19].

В некоторых работах получены противоположные результаты, показывающие, что естественные пожары и искусственные палы вызывают сокращение грибной биомассы в почве [39, 149], хотя искусственные палы влияют на это в меньшей степени [29].

Очевидно, что отложенное (долгосрочное) воздействие на биомассу почвенных грибов зависит от интенсивности пожаров. Например, спустя 3 года после природного пожара в сообществе Picea mariana грибная биомасса, рассчитанная на основе количественного анализа эргостеролов, была сходна с таковой в сообществах, слабо затронутых пожаром, или таких, где не было пожара. В то же время эргостерол не был обнаружен в почвах, подвергнутых сильному воздействию пожара [19].

Еще 15 лет назад оценка влияния пожара на макромицеты проводилась на основе учета их плодовых тел. Например, было показано, что некоторые представители Pezizales (Ascomycota) уже спустя 6 недель после пожара активно плодоносят, причем высокая активность плодоношения сохраняется до 2 лет [120].

Данные о влиянии пожара на активность плодоношения эктомикоризообразующих базидиомицетов (ЭМ) довольно противоречивы. Так было зарегистрировано уменьшение обилия плодовых тел и видоизменение структуры сообществ ЭМ [31].

Напротив, некоторые авторы наблюдали отсутствие значимого влияния пожаров слабой интенсивности на видовое богатство этих грибов в сообществах Pinus sylvestris L., тогда как показатель выравненности был ниже после воздействия пожара. Методом RFLP на основе анализа ITS было показано, что видовой состав ЭМ в почве только на 54\% соответствует тому, что наблюдается при оценке путем учета плодовых тел в природе [78]. Например, то, что некоторые из Pezizales могут формировать экто- или эндомикоризу с хвойными при отсутствии пожара, но существовать как сапротрофы в верхнем горизонте почвы (15 см) после пожара, было установлено именно с помощью RFLP [59].

Совсем недавно появились первые исследования по изучению влияния пожаров на микробные и грибные сообщества с использованием методов NGS $[24,111$, $128,141,143]$.

Так, например, исследование влияния пожара на микобиоту сосняков северо-восточной Финляндии, проведенное с помощью метода пиросеквенирования, выявило определенные закономерности изменения состава и встречаемости некоторых таксонов в зависимости от давности пожара [141]. Было показано, что видовое разнообразие грибов достоверно различается между площадками с давностью пожара 2 года и 152 года. Ожидаемое видовое богатство, рассчитанное на основании индекса Chaol, значительно различалось в паре площадок с давностью пожара 60 лет и 152 года и мало различалось между площадками с давностью пожара 42 года и 60 лет. В целом оценка богатства OTU и разнообразия указывает на уменьшение видового богатства и разнообразия гри- бов по мере увеличения давности пожара. Показано, что грибы из Ascomycota доминируют на площадке с 2-летним периодом после пожара, тогда как представители Basidiomycota были наиболее многочисленны на площадках с давностью пожара более 42 лет. Регрессионный анализ относительного обилия показал, что разнообразие и встречаемость аскомицетов постепенно уменьшается по мере увеличения давности пожара, тогда как среди базидиомицетов эти показатели, наоборот, увеличиваются. Авторы смогли установить родовую или видовую принадлежность примерно 30\% OTUs. Из всех прочитанных последовательностей 9\% (250 OTU) относились к Ascomycota и 44\% (291 OTU) - к Basidiomycota.

Сравнительный анализ метагеномных данных показывает, что в таежных экосистемах грибные сообщества наиболее чувствительны к воздействию пожаров [39, 72, 111]. Для восстановления грибных сообществ в таежных хвойных лесах требуется от 10 до 25 лет. На основании многолетних наблюдений методами метагеномики на платформе Illumina MiSeq и с использованием последовательности локуса ITS2 было выяснено, что частые искусственные палы в сообществах Pinus taeda L. (юго-восток США) поддерживают стабильное разнообразие и видовое богатство грибных сообществ на длительном отрезке времени (до 25 лет). Подчеркивается, что среди ЭМ грибов есть таксоны, которые плохо переносили пожары (1 OTU в сем. Thelephoraceae; 3 OTU в роде Russula, 1 таксон в роде Sistotrema), и, наоборот, таксоны, рост которых стимулировали частые пожары (1 OTU в сем. Russulaceae, 4 - Thelephoraceae, 1 в роде Amanita, 1 - Clavulina, 1 - Tylospora, 1 - Ramaria и 3 -Suillus). Наиболее заметной была положительная реакция одного таксона из рода Suillus и 4 таксонов из сем. Thelephoraceae [111]. Авторы приходят к выводу, что частое выжигание поддерживает сообщества грибов почвы, которые в свою очередь способствуют развитию видов растений, адаптированных к частым пожарам.

Значительно меньше известно о влиянии пожаров на дереворазрушающие грибы, в том числе обитающие в древесине, погруженной в почву. Предполагается, что, поскольку лесной пожар - естественное явление, то дереворазрушающие грибы должны быть адаптированы к его воздействию или даже зависеть от него [134]. Кроме того, пожары усиливают гетерогенность древесины, включая не затронутую пожаром и обуглившуюся, что создает новые местообитания для грибов. Однако пожар может также уничтожать большое количество мертвой древесины [83], в частности, бревна, пни и сухостойные деревья, тем самым сокращая разнообразие потенциальных субстратов для грибов. Известно, что быстрым ответом сообществ дереворазрушающих грибов на пожар является обеднение их разнообразия и видового богатства [79].

Однако значительные изменения, производимые пожаром в окружающей среде, создают возможности для формирования новых грибных группировок [121].

Анализ ДНК грибов, выделенной из образцов гнилой древесины, методом DGGE и 4-5-4 пиросеквенирования проводился рядом скандинавских и финских ученых [87, 116, 117, 123, 124]. Общим трендом для большинства грибов, живущих в древесине, являет- 
ся уменьшение их обилия в первые два года после пожара и восстановление через 4 года. Впоследствии плодовые тела грибов этой экологической группы часто находят на поврежденной пожаром древесине и даже на обугленной древесине, например, виды рода Athelia, Tomentella и Tomentellopsis, а также Botryobasidium obtusisporum, Phanerochaete sordida, Phlebia subserialis и Trichoderma viride [134].

В России изучение влияния пожаров на микобиоту почв методами метагеномики было начато в 2016 г. на территории Нижне-Свирского государственного природного заповедника (Северо-Запад России, Ленинградская область). Первые результаты планируется опубликовать в ближайшее время. В частности, в результате предварительного анализа установлено, что богатство эктомикоризных грибов в почве и в гнилой древесине возрастает по мере увеличения сроков давности пожара, причем появляются таксоны, не встреченные на ранних стадиях пирогенной сукцессии. Это подтверждает уже известную закономерность, что большинство эктомикоризообразователей в лесных сообществах не формируют плодовых тел или отличаются необильным и редким плодоношением и могут быть обнаружены только молекулярными методами. На состав порядков давность пожара не влияет, везде по числу прочтений доминируют аскомицеты и базидиомицеты. Отмечено увеличение присутствия мицелия ЭМГ на гнилой древесине по мере возрастания сроков давности пожара.

\section{Заключение}

Таким образом, несоответствие наблюдаемого видового и экологического разнообразия грибов и грибообразных протистов реально существующему («скрытое разнообразие») является серьезной методической проблемой. На данном этапе развития науки она может быть решена только на основе комбинации метагеномного подхода, классического молекулярного и морфологического анализа. Лишь применение молекулярных методов, основанных на выделении грибной ДНК и секвенировании отдельных участков генома, дает возможность наиболее достоверной идентификации микобионтов на видовом уровне, на уровне популяций и даже на уровне отдельных организмов [88]. Крайне необходимо накопление электронных библиотек качественных последовательностей маркерных генов, относящихся к определенным морфовидам. Это одна из главных задач специалистов и экспертов по отдельным группам организмов, так как идентификация и интерпретация последовательностей, относящихся к операционным таксономическим единицам (OTU), выявленным методами метагеномики, часто затруднены из-за недостатка данных о генетическом, морфологическом и экологическом разнообразии морфологических видов.

Благодарности: работа выполнена при поддержке гранта РФФИ 15-29-02622 офи-м.

\section{Литература}

\section{Список русскоязычной литературы}

1. Волобуев СВ. Афиллофороидные грибы Орловской области: таксономический состав, распространение, экология. СПб.: Лань; 2015.

2. Гонгальский КБ. Лесные пожары и почвенная фауна. М.: Товарищество научных изданий КМК; 2014

3. Горшков ВВ, Баккал ИЮ. Изменение напочвенного покрова дренированных сосновых лесов Кольского полуострова с разной давностью пожара в период с 1991 по 2006 г. Актуальные проблемы геоботаники III Bceроссийская школа-конференция. Лекции; Петрозаводск: КарНЦ РАН; 2007. с. 383-96.

4. Змитрович ИВ. Средняя тайга Карельского перешейка: зональные, интразональные и экстразональные явления. Вестник экологии, лесоведения и ландшафтоведения. 2011;(11):54-76.

5. Щеглова ЕГ. Влияние низовых пожаров на лиственные леса Оренбуржья. Актуальные вопросы современной науки. 2012;10:15-20.

Общий список литературы/Reference List

1. Volobuev SV. Afilloforoidnye Griby Orlovskoy Oblasti: Taksonomicheskiy Sostav, Rasprostranennost', Ekologiya. [Aphyllophoroid Fungi of Oryol Region: Taxonomical Structure, Distribution, Ecology]. Saint Petersburg: Lan'; 2015. (In Russ.)
2. Gongalskiy KB. Lesnye Pozhary i Pochvennaya Fauna. [Forest Fires and Soil Fauna]. Moscow: KMK; 2014. (In Russ.)

3. Gorshkov VV, Bakkal IYu. [Changes in the ground cover of drained pine forests of Kola Peninsula with different prescriptions of fire in 1991-2006]. In: Aktualnye Problemy Geobotaniki III Vserossiskaya Shkola-Konferentsiya; Petrozavodsk: KarNC RAN; 2007. p. 383-96. (In Russ.)

4. Zmitrovich IV. [Middle taiga of Karelian Isthmus: zonal, intrazonal and extrazonal phenomena]. Vestnik Ekologii Lesovedeniya i Landshaftovedeniya. 2011;(11):54-76. (In Russ.)

5. Shcheglova EG. [The influence of ground fires on the deciduous forests of Orenburg Region]. Aktualnye Voprosy Sovremennoy Nauki. 2012;10:15-20. (In Russ.)

6. Abarenkov K, Nilsson HR, Larsson K-H, Alexander IJ, Eberhardt U, Erland S, Høiland K, Kjøller R, Larsson E, Pennanen T, Sen R, Taylor AFS, Tedersoo L, Ursing BM, Vrålstad T, Liimatainen K, Peintner U, Kõljalg U. The UNITE database for molecular identification of fungi - recent updates and future perspectives. New Phytologist. 2010;186(2):281-5.

7. Adl SM, Simpson AGB, Lane CE, Lukeš J, Bass D, Bowser SS, Brown MW, Burki F, Dunthorn M, Hampl V, Heiss A, Hoppenrath 
M, Lara E, le Gall L, Lynn, DH, McManus H, Mitchell EAD, Mozley-Stanridge SE, Parfrey LW, Pawlowski J, Rueckert S, Shadwick L, Schoch CL, Smirnov A, Spiegel FW. The revised classification of eukaryotes. J Eukaryot Microbiol. 2012;59(5):429-514.

8. Agerer R. Colour Atlas of Ectomycorrhizae. Einhorn-Verlag: Schwäbisch Gmünd; 1987-2002.

9. Allen MF. The Ecology of Mycorrhizae Cambridge. Cambridge: Cambridge University Press; 1991.

10. Anderson IC, Cairney JWG. Diversity and ecology of soil fungal communities: increased understanding through the application of molecular techniques. Environ Microbiol. 2004;6:769-79.

11. Avis PG, Dickie IA, Mueller GM. A 'dirty' business: testing the limitations of terminal restriction fragment length polymorphism (TRFLP) analysis of soil fungi. Molec Ecol. 2006; 15:873-82.

12. Baar J, Horton TR, Kretzer AM, Bruns TD. Mycorrhizal colonization of Pinus muricata from resistant propagules after a stand-replacing wildfire. New Phytologist. 1999;143:409-18.

13. Baas D, Richard TA. Three reasons to reevaluate fungal diversity 'on Earth and in the ocean’. Fungal Biol Rev. 2011;25:159-64.

14. Babos M. Mycological examination of sawdust depots in Hungary. Stud Bot Hungar. 1981;15:31-44.

15. Bailly J, Fraissinet-Tachet L, Verner M-C, Debaud J-C, Lemaire M, Wesolowski-Louvel M, Marmeisse R. Soil eukaryotic functional diversity, a metatranscriptomic approach. ISME J. 2007;1:632-42.

16. Baldrian $P$, Kolařík $M$, Štursová $M$, Kopecký J, Valášková V, Větrovský T, Žifčáková L, Snajdr, J, Rídl J, Vlček Č, Vořrišková J. Active and total microbial communities in forest soil are largely different and highly stratified during decomposition. ISME Journal. 2012;6:248-58.

17. Benson DA, Clark K, Karsch-Mizrachi I, Lipman DJ, Ostell J, Sayers EW. GenBank. Nucleic Acids Research. 2015;43(Database issue):D30-D5.

18. Bent E, Kiekel P, Brenton R, Taylor DL. Root-associated ectomycorrhizal fungi shared by various boreal forest seedlings naturally regenerating after a fire in interior Alaska and correlation of different fungi with host growth responses. Appl Environ Microbiol. 2011;77: 3351-9.

19. Bergner B, Johnstone J, Treseder KK. Experimental warming and burn severity alter soil CO2 flux and soil functional groups in a recently burned boreal forest. Global Change Biology. 2004;10:1996-2004.

20. Bik HM, Porazinska DL, Creer S, Caporaso JG, Knight R, Caporaso JG, Knight R, Kelley W, Thomas WK. Sequencing our way towards understanding global eukaryotic biodiversity. Trends Ecol Evol. 2012;27:233-43.

21. Blackwell M. The Fungi: 1, 2, 3 ... 5.1 million species? Am J Bot. 2011;98(3):426-38.

22. Bledsoe CS, Tennison K., Lopushinsky W. Survival and growth of outplanted Douglas-fir seedlings inoculated with mycorrhizal fungi. Can J Forest Res. 1982:720-3.

23. Bonfante P, Genre A. Mechanisms underlying beneficial plant-fungus interactions in mycorrhizal symbiosis. Nature Comm. 2010;1(48):1-11.

24. Brown SP, Callaham MAJ, Oliver AK, Jumpponen A. Deep Ion Torrent sequencing identifies soil fungal community shifts after frequent prescribed fires in a southeastern US forest ecosystem. FEMS Microbiol Ecol. 2013;86(3):557-66.

25. Brundrett MC. Mycorrhizal associations and other means of nutrition of vascular plants: understnding global diversity of host plants by resolving conflicting information and developing reliable means of diagnosis. Plant Soil. 2009;320:37-77.

26. Bruns TD, Szaro TM, Gardes M, Cullings KW, Pan JJ, Taylor DL, Horton TR, Kretzer A, Garbelotto M, Li Y. A sequence database for the identification of ectomycorrhizal basidiomycetes by phylogenetic analysis. Molec Ecol. 1998;7(3):257-72.

27. Buée M, Reich M, Murat C, Morin E, Nilsson RH, Uroz S, Martin F. 454 pyrosequencing analyses of forest soils reveal an unexpected high fungal diversity. New Phytologist. 2009;184: 449-56.

28. Cairney JW, Bastias BA. Influences of fire on forest soil fungal communities. Can J Forest Res. 2007;37(2):207-15.

29. Choromanska U, DeLuca TH. Prescribed fire alters the impact of wildfire on soil biochemical properties in a ponderosa pine forest. Soil Sci Soc Am J. 2001;65:232-8.

30. Clissmann F, Fiore-Donno AM, Hoppe B, Krüger D, Kahl T, Unterseher M, Schnittler M. First insight into dead wood protistan diversity: a molecular sampling of bright-spored Myxomycetes (Amoebozoa, slime-moulds) in decaying beech logs. FEMS Microbiol Ecol. 2015;91: pii: fiv050. doi: 10.1093/femsec/fiv050

31. Dahlberg A. Effects of fire on ectomycorrhizal fungi in Fennoscandian boreal forests. Silva Fenn. 2002;36:69-77.

32. Dahlberg A, Jonsson L, Nylund J-E. Species diversity and distribution of biomass above and below ground among ectomycorrhizal fungi in an old-growth Norway spruce forest in south Sweden. Can J Bot. 1997;75(8):1323-35.

33. Damon C, Lehembre F, Oger-Desfeux C, Luis P, Ranger J. Metatranscriptomics reveals the diversity of genes expressed by eukaryotes in forest soils. PLoS ONE. 2012;7(1):e28967.

34. Dance A. What lies beneath. Nature. 2008;455:724-5.

35. Danielson RM, Visser S. Host response to inoculation and behavior of introduced and indigenous ectomycorrhizal fungi of jack pine grown on oil-sands tailings. Can J Forest Res. 1989;19:1412-21.

36. Davison J, Opik M, Zobel M, Vasar M, Metsis M, Moora M. Communities of arbuscular mycorrhizal fungi detected in forest soil are spatially heterogeneous but do not vary throughout the growing season. PLoS One. 2012;7:e41938. 
37. Dickie IA, Xu B, Koide RT. Vertical distribution of ectomycorrhizal hyphae in soil as shown by T-RFLP analysis. New Phytologist. 2002;156:527-35.

38. Domsch KH, Gams W, Anderson T-H. Compendium of soil fungi. New York: Academic Press; 1980

39. Dooley SR, Treseder KK. The effect of fire microbial biomass: a metaanalysis of field studies. Biogeochemistry. 2012;109:49-61.

40. Dumbrell AJ, Ashton PD, Aziz N, Feng G, Nelson M, Dytham C, Fitter AH, Helgason T. Distinct seasonal assemblages of arbuscular mycorrhizal fungi revealed by massively paralle pyrosequencing. New Phytologist. 2011;190: 794-804.

41. Egger KN, Hibbett DS. The evolutionary implications of exploitation in mycorrhizas. Can J Bot. 2004;82:1110-21.

42. Ekelund F, Ronn R. Notes on protozoa in agricultural soil with emphasis on heterotrophic flagellates and naked amoebae and their ecology. FEMS Microbiol Rev. 1994;15:321-53.

43. Erland S, Taylor AFS. Resupinate ectomycorrhizal fungal genera. Ectomycorrhizal fungi: key genera in profile. Heidelberg: Springer Verlag; 1999. p. 347-63.

44. Feest A, Madelin MF. A method for the enumeration of myxomycetes in soil and its application to a wide range of soils. FEMS Microbiol Lett. 1985;31(2):103-9.

45. Feest A. Numbers of myxogastrids and other protozoa recovered from Bohemian soils. Ekologia. 1986;5:125-33.

46. Feest A. The quantitative ecology of soil mycetozoa. Progr Protistol. 1987;2:331-61.

47. Feest A, Madelin MF. Numerical abundance of myxomycetes (myxogastrids) in soil in the West of England. Microbial Ecol. 1985;31:353-60.

48. Feest A, Madelin MF. Seasonal population changes of myxomycetes and associated organisms in five non-woodland soils, and correlations between their numbers and soil characteristics. FEMS Microbiol Rev. 1988;53(3-4):141-52.

49. Feng Y, Schnittler M. Sex or no sex? Group I introns and independent marker genes reveal the existence of three sexual but reproductively isolated biospecies in Trichia varia (Myxomycetes). Organisms Divers Evolut. 2015;15(4):631-50.

50. Feng Y, Klahr A, Janik P, Ronikier A, Hoppe T, Novozhilov YK, Schnittler M. What an intron may tell: several sexual biospecies coexist in Meriderma spp. (Myxomycetes). Protist. 2016;167(3):234-53.

51. Fiore-Donno A-M, Berney C, Pawlowski J, Baldauf SL. Higher-order phylogeny of plasmodial slime molds (Myxogastria) based on elongation factor 1-A and small subunit rRNA gene sequences. J Eukaryot Microbiol. 2005;52:1-10.

52. Fiore-Donno AM, Meyer M, Baldauf SL, Pawlowski J. Evolution of dark-spored Myxomycetes (slime-molds): molecules versus morphology. Mol Phylogenet Evol. 2008;46(3): 878-89.

53. Fiore-Donno AM, Novozhilov YK, Meyer M, Schnittler M. Genetic Structure of two protist species (Myxogastria, Amoebozoa) suggests asexual reproduction in sexual amoebae. PLoS ONE. 2011;6(8):e22872.

54. Fiore-Donno AM, Weinert $\mathrm{J}$, Wubet $\mathrm{T}$, Bonkowski M. Metacommunity analysis of amoeboid protists in grassland soils. Sci Rep. 2016;6:19068.

55. Fiore-Donno AM, Nikolaev SI, Nelson M, Pawlowski J, Cavalier-Smith T, Baldauf SL. Deep Phylogeny and Evolution of Slime Moulds (Mycetozoa). Protist. 2010;161(1):55-70.

56. Fiz-Palacios O, Romeralo M, Ahmadzadeh A, Weststrand S, Ahlberg PE, Baldauf S. Did terrestrial diversification of Amoebas (Amoebozoa) occur in synchrony with land plants? PLoS ONE. 2013;8(9):e74374.

57. Foissner W. Biogeography and dispersal of micro-organisms: a review emphasizing Protists. Acta Protozool. 2006;45:111-36.

58. Foissner W. Protist diversity and distribution: some basic considerations. Biodiversity Conservation. 2008; 17:235-42.

59. Fujimura KE, Smith JE, Horton TR, Weber NS, Spatafora JW. Pezizalean mycorrhizas and sporocarps in ponderosa pine (Pinus ponderosa) after prescribed fires in eastern Oregon, USA. Mycorrhiza. 2005;15:79-86.

60. Gardes M, Bruns TD. Community structure of ectomycorrhizal fungi in a Pinus muricata forest: above- and below-ground views. Can J Bot. 1996; $74: 1572-83$.

61. Geml J, Timling I, Robinson CH, Lennon N, Nusbaum HC, Brochmann C, Noordeloos ME, Taylor DL. An arctic community of symbiotic fungi assembled by long-distance dispersers: phylogenetic diversity of ectomycorrhizal basidiomycetes in Svalbard based on soil and sporocarp DNA. J Biogeography. 2012;39(1): 74-88.

62. Gilbert OM, Queller DC, Strassmann JE. Discovery of a large clonal patch of a social amoeba: implications for social evolution. Molec Ecol. 2009;18:1273-81.

63. Guinto DF, Xu ZH, House APN, Saffigna PG. Soil chemical properties and forest floor nutrients under repeated prescribed-burning in eucalypt forests of south-east Queensland, Australia. NZ J Forest Sci. 2001;31:170-87.

64. Hanson CA, Fuhrman JA, Horner-Devine MC, Martiny JBH. Beyond biogeographic patterns: processes shaping the microbial landscape. Nat Rev Microbiol. 2012;10:497-506.

65. Hart SC, DeLuca TH, Newman GS, MacKenzie MD, Boyle SI. Post-fire vegetative dynamics as drivers of microbial community structure and function in forest soils. Ecol Manage. 2005;220:166-84

66. Hart SH, Classen AT, Wright RJ. Long-term interval burning alters fine root and mycorrhizal dynamics in a ponderosa pine forest. J Appl Ecol. 2005;42:752-61.

67. Hawksworth D. The magnitude of fungal diversity: the 1.5 million species estimate revisited. Mycol Res. 2001;105:1422-32.

68. Hibbett DS, Gilbert L-B, Donoghue MJ. Evolutionary instability of ectomycorrhizal 
symbioses in basidiomycetes. Nature. 2000;407:506-8

69. Hibbett DS, Pine EM, Langer E, Langer G, Donoghue MJ. Evolution of gilled mushrooms and puffballs inferred from ribosomal DNA sequences. Proc Natl Acad Sci USA 1997;94:12002-6.

70. Hibbett DS, Ohman A, Glotzler D, Nuhn M, Kirk PM, Nilsson RH. Progress in molecular and morphological taxon discovery in Fungi and options for formal classification of environmental sequences. Fungal Biology Reviews. 2011;25:38-47.

71. Hibbett DS, Binder M, Bischoff JF, Blackwell M, Cannon PF, Eriksson OE, Huhndorf S, James T, Kirk PM, Lücking R, Thorsten Lumbsch H, Lutzoni F, Matheny PB, McLaughlin DJ, Powell MJ, Redhead S, Schoch CL, Spatafora JW, Stalpers JA, Vilgalys R, Aime MC, Aptroot A, Bauer R, Begerow D, Benny GL, Castlebury LA, Crous PW, Dai Y-C, Gams W, Geiser DM, Griffith GW, Gueidan C, Hawksworth DL, Hestmark G, Hosaka K, Humber RA, Hyde KD, Ironside JE, Kõljalg U, Kurtzman CP, Larsson K-H, Lichtwardt R, Longcore J, Miądlikowska J, Miller A, Moncalvo J-M, Mozley-Standridge S, Oberwinkler F, Parmasto E, Reeb V, Rogers JD, Roux C, Ryvarden L, Sampaio JP, Schüßler A, Sugiyama J, Thorn RG, Tibell L, Untereiner WA, Walker C, Wang Z, Weir A, Weiss M, White MM, Winka K, Yao Y-J, Zhang N. A higher-level phylogenetic classification of the Fungi. Mycol Res. 2007;111(5):509-47.

72. Holden SR, Gutierrez A, Treseder KK. Changes in soil fungal communities, extracellular enzyme activities, and litter decomposition across a fire chronosequence in Alaskan boreal forests. Ecosystems. 2013;16:34-46.

73. Hoppe T. Molecular diversity of myxomycetes near Siegen (Germany). Mycoscience. 2013;54(4):309-13.

74. Horton TR. Molecular approaches to ectomycorrhizal diversity studies: variation in ITS at a local scale. Plant Soil. 2002;244:29-39.

75. Horton TR, Bruns TD. The molecular revolution in ectomycorrhizal ecology: peeking into the black-box. Mol Ecol. 2001:1855-71.

76. Horton TR, Cázares E, Bruns TD. Ectomycorrizal, vesicular-arbuscular and dark septate fungal colonization of bishop pine (Pinus muricata) seedlings in the first 5 months of growth after wildfire. Mycorriza. 1998;8:11-8.

77. Dighton J, White JF. The Fungal Community. Its Organization and Role in the Ecosystem. London-New York-Singapore: Taylor and Francis; 2005.

78. Jonsson L, Dahlberg A, Nilsson M-C, Zackrisson O, Kare'n O. Ectomycorrhizal fungal communities in late-successional Swedish boreal forests, and their composition following wildfire. Mol Ecol. 1999;8:205-15.

79. Junninen K, Kouki J, Renvall P. Restoration of natural legacies of fire in European boreal forests: an experimental approach to the effects on wood-decaying fungi. Can J Forest Res. 2008;38:202-15.

80. Kamono A, Meyer M, Cavalier-Smith T, Fukui M, Fiore-Donno A-M. Exploring slime mould diversity in high-altitude forests and grasslands by environmental RNA analysis. FEMS Microbiol Ecol. 2013;84:98-109.

81. Kårén O, Högberg N, Dahlberg A, Jonsson L, Nylund JE. Inter- and intraspecific variation in the ITS region of rDNA of ectomycorrhizal fungi in Fennoscandia as detected by endonuclease analysis. New Phytologist. 1997;136:313-25.

82. Kipfer T, Egli S, Ghazoul J, Moser B, Wohlgemuth T. Susceptibility of ectomycorrhizal fungi to soil heating. Fungal Biol. 2010;114:467-72.

83. Knapp EE, Keeley JE, Ballenger EA, Brennan TJ. Fuel reduction and coarse woody debris dynamics with early season and late prescribed fire in a Sierra Nevada mixed conifer forest. Forest Ecol Manage. 2005;208:383-97.

84. Kõljalg U, Nilsson RH, Abarenkov K, Tedersoo L, Taylor AFS, Bahram M, Bates ST, Bruns TD, Bengtsson-Palme J, Callaghan TM, Douglas B, Drenkhan T, Eberhardt U, Dueñas M, Grebenc T, Griffith GW, Hartmann M, Kirk PM, Kohout P, Larsson E, Lindahl BD, Lücking R, Martín MP, Matheny PB, Nguyen NH, Niskanen T, Oja J, Peay KG, Peintner U, Peterson M, Põldmaa K, Saag L, Saar I, Schüßler A, Scott JA, Senés C, Smith ME, Suija A, Taylor DL, Telleria MT, Weiss $\mathrm{M}$, Larsson K-H. Towards a unified paradigm for sequence-based identification of fungi. Molec Ecol. 2013;22(21):5271-7.

85. Kõljalg U, Larsson KH, Abarenkov K, Nilsson RH, Alexander IJ, Eberhardt U, Erland S, Høiland K, Kjøller R, Larsson E, Pennanen T, Sen R, Taylor AFS, Tedersoo L, Vrålstad T, Ursing BM. UNITE: a database providing web-based methods for the molecular identification of ectomycorrhizal fungi. New Phytologist. 2005;166(3):1063-8.

86. Kubart A, Vasaitis R, Stenlid J, Dahlberg A. Fungal communities in Norway spruce stumps along a latitudinal gradient in Sweden. Forest Ecol Manage. 2016;371:50-8. 2016: http://dx.doi. org/10.1016/j.foreco.2015.12.017.

87. Kubartová A, Ottosson A, Dahlberg A, Stenlid J. Patterns of fungal communities among and within decaying logs, revealed by 454 sequencing. Molec Ecol. 2012;21(18):4514-32.

88. Landeweert R, Veenman C, Kuyper TW, Fritze H, Wernars K, Smit E. Quantification of ectomycorrhizal mycelium in soil by real-time PCR compared to conventional quantification techniques. FEMS Microbiology Ecology. 2003;45:283-92.

89. Landeweert R, Leeflang P, Kuyper TW, Hoffland E, Rosling A, Wernars K, Smit E. Molecular Identification of Ectomycorrhizal Mycelium in Soil Horizons. Appl Environ Microbiol. 2003;69(1):327-33.

90. Lentendu G, Zinger L, Manel S, Coissac E, Choler P, Geremia RA, Melodelima C. Assessment of soil fungal diversity in different alpine tundra habitats by means of pyrosequencing. Fungal Diversity. 2011;49:113-23.

91. Lesaulnier C, Papamichail D, McCorkle S, Ollivier B, Skiena S, Taghavi S, Zak D, van der Lelie D. Elevated atmospheric CO2 affects soil microbial diversity associated with trembling aspen. Environ Microbiol. 2008;10:926-41. 
92. Lim YW, Kim BK, Kim C, Jung HS, Kim BS, Lee JH, Chun J. Assessment of soil fungal communities using pyrosequencing. J Microbiol. 2010;48:284-9.

93. Lindahl BD, Nilsson RH, Tedersoo L, Abarenkov K, Carlsen T, Kjøller R, Kõljalg U, Pennanen T, Rosendahl S, Stenlid J, Kauserud H. Fungal community analysis by high-throughput sequencing of amplified markers - a user's guide. New Phytologist. 2013;199:288-99.

94. Liu QS, Yan SZ, Chen SL. Further resolving the phylogeny of Myxogastria (slime molds) based on COI and SSU rRNA genes. Genetika. 2015;51(1):46-53

95. Luoma DL, Eberhart JL, Amaranthus MP. Biodiversity of ectomycorrhizal types from southwest Oregon. In: Conservation and Management of Native Plants and Fungi; Corvallis, OR: Native Plant Society of OREGON;1997. p. 249-53.

96. Mah K, Tackaberry LE, Egger KN, Massicotte HB. The impacts of broadcast burning after clearcutting on the diversity of ectomycorrhizal fungi associated with hybrid spruce seedlings in central British Columbia. Can J Forest Res. 2001;31:224-35.

97. Martin MP, Lado C, Johansen S. Primers are designed for amplification and direct sequencing of ITS region of rDNA from Myxomycetes. Mycologia. 2003;95(3):474-79.

98. Martiny HJB, Bohannan BJM, Brown JH, Colwell RK, Fuhrman JA, Green JL, HornerDevine MC, Kane M, Krumins JA, Kuske CR, Morin PJ, Naeem S, Øvreås L, Reysenbach A-L, Smith VH, Staley JT. Microbial biogeography: putting microorganisms on the map. Nat Rev Microbiol. 2006;4:102-12.

99. Mehmann B, Egli S, Bravs GH, Brunner I. Coincidence between molecularly or morphologically classified ectomycorrhizal morphotypes and fruitbodies in a Spruce forest Biotechnology of Ectomycorrhizae: Molecular Approaches. London: Plenum Press; 1995. p. 41-52.

100. Menkis A, Burokiene D, Stenlid J, Stenström E. High-throughput sequencing shows high fungal diversity and community segregation in the rhizospheres of container-grown conifer seedlings. Forests. 2016;7(2):44. doi: 10.3390/ f7020044.

101. Moon-van der Staay SY, Tzeneva VA, van der Staay GW, de Vos WM, Smidt H, Hackstein JH. Eukaryotic diversity in historical soil samples. FEMS Microbiol Ecol. 2006;57:420-8.

102. Mueller GM, Bills GF, Foster MS Biodiversity of Fungi: Inventory and Monitoring Methods. Amsterdam-Boston: Elsevier; 2004.

103. Nagy LG, Petkovits T, Kovács GM, Voigt K, Vágvölgyi C, Papp T. Where is the unseen fungal diversity hidden? A study of Mortierella reveals a large contribution of reference collections to the identification of fungal environmental sequences. New Phytologist. 2011;191(3):789-94.

104. Neary DG, Ryan KC, DeBano LF, editors. Wildland Fire in Ecosystems: Effects of Fire on Soils and Water. General Technical Report RMRS GTR-42-volume 4. Ogden, UT: U.S. Department of Agriculture, Forest Service, Rocky Mountain Research Station; 2008.

105. Neary DG, Klopatek CC, DeBano LF, Ffolliott PF. Fire effects on belowground sustainability: a review and synthesis. Forest Ecol Manage. 1999;122:51-71.

106. Niemelä T, Renvall P, Penttilä R. Interactions of fungi at late stages of wood decomposition. Ann Bot Fenn. 1995;32(3):141-52.

107. Novozhilov YK, Schnittler M, Erastova DA, Okun MV, Schepin ON, Heinrich E. Diversity of nivicolous myxomycetes of the Teberda State Biosphere Reserve (Northwestern Caucasus, Russia). Fungal Diversity. 2013;59(1):109-30.

108. Novozhilov YK, Okun MV, Erastova DA, Shchepin ON, Zemlyanskaya IV, GarcíaCarvajal E, Schnittler M. Description, culture and phylogenetic position of a new xerotolerant species of Physarum. Mycologia. 2013;105:1535-46.

109. O'Brien HE, Parrent JL, Jackson JA, Moncalvo J-M, Vilgalys R. Fungal community analysis by large-scale sequencing of environmental samples. Appl Environ Microbiol. 2005;71(9):5544-50.

110. Okun MV, Fiore-Donno AM, Novozhilov YK, Zemlianskaia IV, Erastova DA (eds). Molecular Phylogeny and Phylogeography of Physarum notabile (Myxomycetes). In: 7th Int Congress on Systematic and Ecology of Myxomycetes. Recife, Brazil; 2011

111. Oliver AK, Callaham Jr. MA, Jumpponen A. Soil fungal communities respond compositionally to recurring frequent prescribed burning in a managed southeastern US forest ecosystem. Forest Ecol Manage. 2015;345:1-9.

112. Öpik M, Metsis M, Daniell TJ, Zobel M, Moora M. Large-scale parallel 454 sequencing reveals host ecological group specificity of arbuscular mycorrhizal fungi in a boreonemoral forest. New Phytologist. 2009;184:424-37.

113. Orgiazzi A, Lumini E, Nilsson $\mathrm{RH}$, Girlanda M, Vizzini A. Unravelling soil fungal communities from different mediterranean landuse backgrounds. PLoS ONE. 2012;7(4):e34847. doi: 10.1371/journal.pone.0034847.

114. Orgiazzi A, Bianciotto V, Bonfante P, Daghino S, Ghignone S, Lazzari A, Lumini E, Mello A, Napoli C, Perotto S, Vizzini A, Bagella S, Murat C, Girlanda M. 454 Pyrosequencing Analysis of Fungal Assemblages from Geographically Distant, Disparate Soils Reveals Spatial Patterning and a Core Mycobiome. Diversity. 2013;5:73-98.

115. Ottosson E, Nordén J, Dahlberg A, Edman M, Jönsson M, Larsson KH, Olsson J, Penttilä R, Stenlid J, Ovaskainen O. Species associations during the succession of wood-inhabiting fungal communities. Fungal Ecol. 2014;11:17-28.

116. Ovaskainen O, Schigel D, Ali-Kovero H, Auvinen P, Paulin L, Nordén B, Nordén J. Combining high-throughput sequencing with fruit body surveys reveals contrasting life-history strategies in fungi. ISME J. 2013;7:1696-709.

117. Ovaskainen O, Nokso-Koivisto J, Hottola J, Rajala T, Pennanen T, Ali-Kovero H, Miettinen O, Oinonen P, Auvinen P, Paulin L, Larsson K-H, Mäkipää R. Identifying wood-inhabiting fungi 
with 454 sequencing - what is the probability that BLAST gives the correct species? Fungal Ecol. 2010;3:274-83.

118. Pawlowski J, Audic S, Adl S, Bass D, Belbahri L, Cédric Berney C, Bowser SS, Cepicka I, Decelle J, Dunthorn M, Fiore-Donno A-M, Gile GH, Holzmann M, Jahn R, Jirků M, Keeling PJ, Kostka M, Kudryavtsev A, Lara E, Lukeš J, Mann DJ, Mitchell EAD, Nitsche F, Romeralo M, Saunders GW, Simpson AGB, Smirnov AV, Spouge JL, Stern RF, Stoeck T, Zimmermann J, Schindel D, de Vargas C. CBOL Protist Working Group: Barcoding eukaryotic richness beyond the Animal, Plant, and Fungal Kingdoms. PLoS Biol. 2012 10(11):e1001419.

119. Peay KG, Kennedy PG, Bruns TD. Fungal community ecology: a hybrid beast with a molecular master. Bioscience. 2008;58:799-810.

120. Petersen PM. Danish fireplace fungi: an ecological investigation of fungi on burns. Dan Bot Ark. 1970;27:1-97.

121. Pugh GJF, Boddy L. A view of disturbance and life strategies in fungi. Proc Roy Soc Edinburgh. 1988;94B:3-11.

122. Ragon M, Fontaine MC, Moreira D, LópezGarcía P. Different biogeographic patterns of prokaryotes and microbial eukaryotes in epilithic biofilms. Mol Ecol. 2012;21:3852-68.

123. Rajala T, Peltoniemi M, Pennanen T, Mäkipää R. Relationship between woodinhabiting fungi determined by molecular analysis (denaturing gradient gel electrophoresis) and quality of decaying logs. Can J Forest Res. 2010;40(12):2384-97.

124. Rajala T, Peltoniemi M, Pennanen T, Mäkipää R. Fungal community dynamics in relation to substrate quality of decaying Norway spruce (Picea abies [L.] Karst.) logs in boreal forests. FEMS Microbiol. Ecol. 2012:1-12.

125. Rappe MS, Giovannoni SJ. The uncultured microbial majority. Annu Rev Microbiol. 2003:369-94.

126. Read DJ. Mycorrhizas in ecosystems. Experentia. 1991;47:376-91.

127. Riesenfeld CS, Schloss PD, Handelsman J. Metagenomics: genomic analysis of microbial communities. Ann Rev Genet. 2004;38:525-52.

128. Rincón A, Santamaría B, Ocaña L, Verdú M. Structure and phylogenetic diversity of postfire ectomycorrhizal communities of maritime pine. Mycorrhiza. 2014;24:131-41.

129. Schmidt MW, Noack AG. Black carbon in soils and sediments: analysis, distribution, implications, and current challenges. Global Biogeochem Cycles. 2000;14:777-93.

130. Schnittler M, Novozhilov YK, Romeralo M, Brown M, Spiegel FW. Fruit body-forming protsts: Myxomycetes and Myxomycete-like organisms (Acrasia, Eumycetozoa). In: Frey W (Ed.). Engler's Syllabus of Plant Families, Part 1/1 Blue-green Algae, Myxomycetes and Myxomycete-like organisms, phytoparasitic protists, heterotrophic Heterokontobionta and Fungi pp. 1/1. 13-th edition ed. Stuttgart: Bornträger; 2012. p. 178.

131. Selosse M-A, Martin F, Bouchard D, Le Tacon F. Structure and dynamics of experimentally introduced and naturally occurring Laccaria sp. Discrete genotypes in a Douglas fir plantation. Appl Environ Microbiol. 1999;65:2006-14.

132. Semenova TA, Morgado LN., Welker JM, Walker MD, Smets E, Geml J. Longterm experimental warming alters community composition of ascomycetes in Alaskan moist and dry tundra. Molec Ecol. 2015;24:424-37.

133. Shchepin ON, Novozhilov YK, Schnittler M. Nivicolous myxomycetes in agar culture: some results and open problems. Protistology. 2014;8(2):53-61.

134. Siitonen J. Forest management, coarse woody debris and saproxylic organisms: Fennoscandian boreal forests as an example. Ecol Bull. 2001;49:11-41.

135. Smith SE, Read DJ. Mycorrhizal symbiosis. 2nd ed. London: Academic Press Ltd.; 1997.

136. Smith SE, Read DJ. Mycorrhizal symbiosis. 3nd ed. London: Academic Press Ltd.; 2008.

137. Sogin ML, Morrison HG, Huber JA, Welch DM, Huse SM, Neal PR, Arrieta JM, Herndl GJ. Microbial diversity in the deep sea and the underexplored "rare biosphere". Proc Natl Acad Sci USA 2006;103(32):12115-20.

138. Stephenson SL, Landolt JC. The vertical distribution of dictyostelids and myxomycetes in the soil/litter microhabitat. Nova Hedwigia. 1996;62:105-17.

139. Stephenson SL, Clark J, Landolt JC. Myxomycetes occurring as single genetic strains in forest soils. System Geogr Plants. 2004;74:2879.

140. Stephenson SL, Fiore-Donno AM, Schnittler M. Myxomycetes in soil. Soil Biol Biochem. 2011;43:2237-42.

141. Sun H, Santalahtia M, Pumpanen J, Köster $\mathrm{K}$, Berninger F, Raffaello $\mathrm{T}$, Jumpponen A, Asiegbu FO, Heinonsalo J. Fungal community shifts in structure and function across a boreal forest fire chronosequence. Appl Environ Microbiol 2015;81(22):7869-80.

142. Taberlet P, Coissac E, Hajibabaei M, Rieseberg LH. Environmental DNA. Mol Ecol. 2012;21:1789-93.

143. Taş N, Prestat E, McFarland JW, Wickland KP, Knight R, Berhe AA, Jorgenson T, Waldrop $\mathrm{MP}$, Jansson JK. Impact of fire on active layer and permafrost microbial communities and metagenomes in an upland Alaskan boreal forest. ISME J. 2014;8:1904-19.

144. Taylor AFS, Alexander I. The ectomycorrhizal symbiosis: Life in the real world. Mycologist. 2005:102-12.

145. Taylor DL, Herriott IC, Stone KE, McFarland JW, Booth MG, Leigh MB. Structure and resilience of fungal communities in Alaskan boreal forest soils. Can J Forest Res. 2010;40:1288-301.

146. Tedersoo L, May TW, Smith ME. Ectomycorrhizal lifestyle in fungi: Global diversity, distribution, and evolution of phylogenetic lineages. Mycorrhiza. 2010;20:217-63.

147. Tedersoo L, Nilsson RH, Abarenkov K, Jairus T, Sadam A, Saar I, Bahram M, Bechem E, Chuyong G, Koljalg U. 454 Pyrosequencing and Sanger sequencing of tropical mycorrhizal 
fungi provide similar results but reveal substantial methodological biases. New Phytologist. 2010;188:291-301.

148. Tedersoo L, Bahram M, Põlme S, Kõljalg U, Yorou NS, Wijesundera R, Ruiz LV, VascoPalacios AM, Thu PQ, Suija A, Smith ME, Sharp C, Saluveer E, Saitta A, Rosas M, Riit T, Ratkowsky D, Pritsch K, Põldmaa K, Piepenbring M, Phosri C, Peterson M, Parts K, Pärtel K, Otsing E, Nouhra E, Njouonkou AL, Nilsson RH, Morgado LN, Mayor J, May TW, Majuakim L, Lodge DJ, Lee SS, Larsson K-H, Kohout P, Hosaka K, Hiiesalu I, Henkel TW, Harend H, Guo L-d, Greslebin A, Grelet G, Geml J, Gates G, Dunstan W, Dunk C, Drenkhan R, Dearnaley J, De Kesel A, Dang T, Chen X, Buegger F, Brearley FQ, Bonito G, Anslan S, Abell S, Abarenkov K. Global diversity and geography of soil fungi. Science. 2014;346(6213).

149. Treseder KK, Mack MC, Cross A. Relationships among fires, fungi, and soil dynamics in Alaskan Boreal Forests. Ecol Applications. 2004;14(6):1826-38.

150. Turetsky MR, Kane ES, Harden JW, Ottmar RD, Manies KL, Hoy E, Kasischke ES. Recent acceleration of biomass burning and carbon losses in Alaskan forests and peatlands. Nat Geosci. 2011;4:27-31.

151. Urich T, Lanzén A, Qi J, Huson DH, Schleper C, Schuster SC. Simultaneous Assessment of Soil Microbial Community Structure and Function through Analysis of the Meta-Transcriptome. PLoS ONE. 2008;3(6):e2527.
152. Voříšková J, Baldrian P. Fungal community on decomposing leaf litter undergoes rapid successional changes. ISME J. 2013;7:477-86.

153. Walbert K, Ramsfield TD, Ridgway HJ, Jones EE. Ectomycorrhizal species associated with Pinus radiata in New Zealand including novel associations determined by molecular analysis. Mycorrhiza. 2010;20:209-15.

154. Ward DM, Bateson MM, Weller R, Ruff-Roberts AL. Ribosomal RNA analysis of microorganisms as they occur in nature. Adv Microb Ecol. 1992;12:219-86.

155. Wikmark OG, Haugen P, Haugli K, Johansen SD. Obligatory group I introns with unusual features at positions 1949 and 2449 in nuclear LSU rDNA of Didymiaceae myxomycetes. Mol Phylogenet Evol. 2007;43(2):596-604.

156. Wikmark OG, Haugen P, Lundblad EW, Haugli K, Johansen SD. The molecular evolution and structural organization of group I introns at position 1389 in nuclear small subunit rDNA of myxomycetes. J Eukaryot Microbiol. 2007;54(1): 49-56.

157. Wurzburger N, Bledsoe CS. Comparison of ericoid and ectomycorrhizal colonization and ectomycorrhizal morphotypes in mixed conifer and pygmy forests on the northern California coast. Can J Bot. 2001;79:1202-10.

158. Yang C, Wanga X, Miller JA, de Blécourt M, Ji Y, Yang C, Harrison RD, Yu DW. Using metabarcoding to ask if easily collected soil and leaf-litter samples can be used as a general biodiversity indicator. Ecol Indicators. 2014;46:379-89.

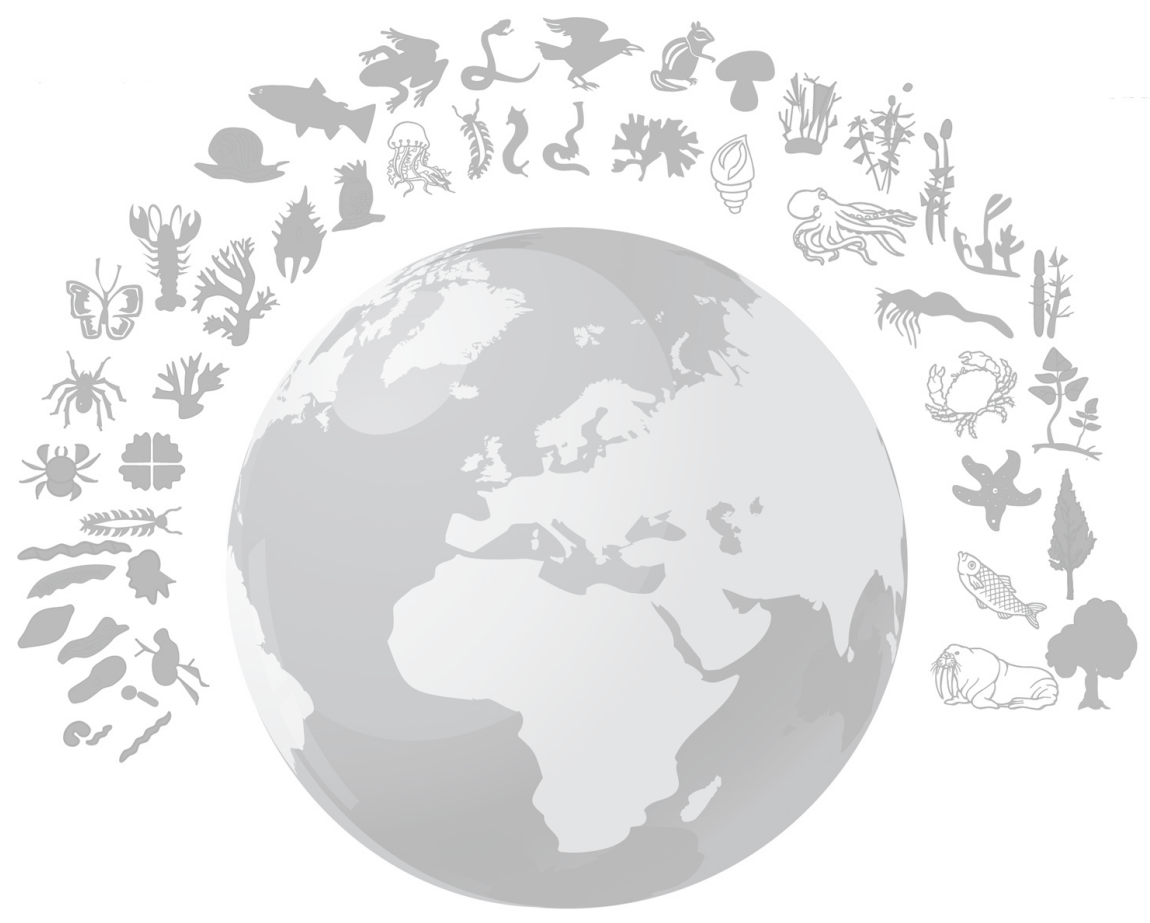

